connection with the main tumor mass had been severed by the surgeon. When this mass was slipped under the liver $i$ ts edge just projecting, felt very much like that of the liver, even having a little indentation corresponding to the notch for the gall-bladder, so that one could clearly see how a mistake of this kind could be made. The surgeon's look of amusement, incredulity and chagrin as the revelation was made was worth remembering.

Other errors $I$ have seen in all departments. In but a few instances could the error be regarded as one due to carelessness. Usually the error has been one of judgment. I mean that the utmost care is usually taken in examination of cases, more care than is usually seen in our hospitals. Too little importance is, at times, as it seems to me, attached to the anamnesis. And there is a tendency with some also, to be drawn away from some cardinal, vital symptom, by the findings of some of the newer methods of diagnosis whose value may not be, as yet, fully established or is, in part, theoretical, e.g., some of the urinary or blood findings, or examination of the stomach contents.

Of the personal characteristics of the various teachers, here is not the place to speak; nor is it in good taste to institute comparisons. Yet I can not forbear to speak in the highest terms of Prof. Chiari, both as a teacher and a scientific man. His lectures and demonstrations are clear, terse, always up with the times. He knows as well what not to tell students as what to tell. He always creates the impression of having an immense reserve fund of knowledge, as telling you what was best for you to know and not all he knows. He works rapidly and accurately, and his post-mortem macroscopic diagnoses rarely have to be corrected by the microscopic or bacteriologic examinations. $\mathrm{He}$ is a strict disciplinarian, demanding of all who work under him quick obedience and the same fidelity and thoroughness that he exemplifies in his own daily work. He is personally watchful over all the details of the work in the Institute and is, as he himself says, very particular and pedantic. He is impartial in his praise or censure of all work done, according as it deserves the one or the other criticism. One who desires to do special work in pathology would find him a careful, inspiring and faithful guide. Were it permissible in a letter of this kind to say more concerning his personal characteristics, I should gladly pay tribute to the many charming and manly qualities of Prof. Chiari.

I can not forbear adding, as a sort of postscript to this letter, a description or rather a mere enumeration of the interesting post-mortem cases seen in the Pathological Institute this morning, June 4 :

1. Tubereulosis of the lungs; secondary basilar meningitis in a child 9 years old ; 2 , broncho-pneumonia in a child; 3 , carcinoma of the liver, probably primary in the liver; icterus gravis; 4, primary carcinoma of the common bileduct; icterus gravis, etc.; 5, splenic-myelogenic leukemia with intercurrent erysipelas as the immediate cause of death; 6 , congenital syphilis in a child with characteristic, well marked changes in heart, lungs, liver, spleen; osteochondritis in all the bones examined-femur both ends, tibia, humerus, ribs. Fracture of femur from version during parturition. Child dead ten minutes post-partum; 7 , infiltrating carcinoma of the stomach with clinical history showing difficulty of diagnosis in so many of these cases, though it had been made correctly (Pribram) in this instance; 8, old appendicitis, suppurative phlebitis, pus still visible in vessels leading from appendix to mesentery, embolic abscesses of liver, pyemia, with retro-pharyngeal and double middle ear abscesses ; 9 , syringomelia ; clinical course somewhat resembling tabes dorsalis; death due to typhoid fever developed during stay in hospital ; 10, old echinococcus cyst of brain, right occipital lobe and encroaching, by press- ure, on posterior horn of lateral ventricle. The cyst, the size of a walnut, was surrounded by cicatricial tissue and a capsule so hard from calcification as to require the bone shears to cut it. Echinococcus hooklets found in the softened mass in the interior. History showed patient healthy up to 15, then epileptic attacks frequently recurring; no focal symptoms; gradually developing paranoia, death at 22 during an epileptic attack. Chiari's theory that at the time of the first attack, seven years before, the infection with the echinococcus occurred, certainly seems rational.

I felt as I witnessed the autopsies and saw these specimens, listened to the epitomized clinical histories and the clear and concise demonstrations of Prof. Chiarl, that I had food for reflection and study for a week.

Very truly yours,

J A MES B. Herrick.

\section{Woman's Hospital and Foundlings' Home.}

Detroit, June 22, 1894.

To the Editor:-Dr. Longyear, President of the medical staff of the Woman's Hospital and Foundlings' Home, has requested me to ask you to notice in your journal the following resolution, which was adopted at a recent meeting of the Trustees of that Hospital :

WhEREAS, The arrangement, providing that nurses from the Correspondence School of Health and Hygiene be allowed to practice in the Woman's Hospital and Foundlings' Home, was made without due consideration; therefore

Resolved, That such arrangement be, and is hereby discontinued from this date, and that a resolution to the effect that no relation whatever exist between the said Correspondence School of Health and Hygiene and the Woman's Hospital and Foundlings' Home be published in medical journals already specified. Mrs. Katharine V. H. Wells, Recording Secretary.

Municipal Hall, Pitts burg, Pa., June 14, 1894.

To the Editor:- Please insert the following in your journal :

To the Members of the Medical Board holding examinations in Pittsburg:-We, a committee representing the candidates from the various colleges, by joint resolution hereby tender for ourselves and colleagues our sincere thanks for the courteous reception extended and the fair treatment shown to us.

Resolved, further, that this resolution be spread in the medical journals of the various States.

Represented:-Drs. A. D. Davidow, Chairman, College of Physicians and Surgeons, Chicago; A. C. Davis, Secretary West Pennsylvania Medical College, Pittsburg, Pa.; W. F. Bayley, University of Tennessee Medical College; W. A. Clementson, Jefferson Medical College, Philadelphia, Pa.; R. B. Cunningham, Louisville Medical College, Kentucky; D. Molyneaux, Royal College of Surgeons, Dublin, Ireland; J. C. Walker, University Medical College, New York; W. J. Cooper, College of Physicians and Surgeons, Baltimore, Md.; Clemens R. Jones, Columbus Medical College, Ohio; John W. Kiger, Medical College of Ohjo; Mary E. Chrystie, Woman's Medical College of Pennsylvania; MeCurdy Bricker, Medical College of Indiana.

\section{SOCIETY NEWS.}

New Hampshire State Medical Society.-The annual meeting of the New Hampshire State Medical Society was held at Concord, June 18 and 19, 1894. The last day's proceedings were as follows:

Officers elected-President, Dr. David P. Goodhue, of Springfield; Vice-President, Dr. E. F. McQuesten, Nashua; Treasurer, Dr. H. II. Felt, Hillsboro Bridge; Secretary, Dr. 